\title{
25 EDITORIAL
}

Los vaivenes del destino a veces golpean con inusitada dureza.

El 15 de octubre pasado falleció Susana Piazzesi, co directora de Estudios Sociales, quien junto a su fundador y director, Darío Macor, fue uno de los principales pilares del trabajo editorial de nuestra publicación. Su labor incansable, precisa y exigente hasta el número actual alimentó durante estos 24 ańos, transcurridos desde el lanzamiento de este emprendimiento, la consolidación de un espacio de producción, debate y diálogo en el ámbito de las ciencias sociales. Con su trabajo en la Secretaría de Redacción primero y en la Dirección luego, Susana contribuyó a esta tarea colectiva que en el transcurso de los últimos años ha perdido a dos intelectuales entrañables en muy diversas maneras: Darío Macor y Ricardo Falcón.

La partida de Susana Piazzesi, constituye una nueva pérdida; de una historiadora e intelectual aguda, que a través de sus trabajos en torno a la década del treinta del siglo XX, aportó a la escritura de la historia política nacional y regional.

Como en otras oportunidades quienes formamos parte de esta revista, asumimos el desafío de continuar con el mismo espíritu fundacional que nos inspiró. Ese espíritu tuvo el valor y la capacidad de construir, con el apoyo de prestigiosos intelectuales del país y del extranjero, una obra perdurable allí donde el terreno se mostraba yermo. La apuesta implicaba a inicios de la década de 1990 que la universidad pública se constituyera en ámbito privilegiado para la producción, circulación y discusión del conocimiento sobre lo político y lo social; desafío que en ese momento recogió la Universidad Nacional del Litoral. En esta nueva etapa sus máximas autoridades han reafirmado, una vez más, el compromiso académico e institucional de continuar con la edición de Estudios Sociales.

La revista, con sus principales hacedores, Darío y Susana, acompañados por el con- 
sejo editorial, la secretaría de redacción, y se impone seguir sosteniendo en adelante. los asistentes de redacción, ha promovido La permanencia de Estudios Sociales evodesde sus inicios una agenda política y ca ya la existencia de una institución, cucultural atenta a las inquietudes acadé- yos frutos se revelan al trascender la finitud micas, así como también a los ciclos de la de nuestras vidas y abonan la persistencia escena nacional e internacional. Tarea que de una construcción colectiva de calidad.

\section{Hugo Quiroga}

Director 